\title{
B20 - JANELA DE OPORTUNIDAdES PARA PRODUÇÃo DE PROTEÍNAS TERAPÊUTICAS DE INTERESSE BRASILEIRO
}

\author{
$\underline{\text { Luciana da Silva Madeira }}^{1}$, Suzana Borshiver ${ }^{2}$ e Nei Pereira Jr. ${ }^{2}$ \\ ${ }^{1}$ Bio-Manguinhos, Fundação Oswaldo Cruz, Rio de Janeiro, Brasil. \\ ${ }^{2}$ Escola de Química, Universidade Federal do Rio de Janeiro, Rio de Janeiro, Brasil.
}

Objetivo: Avaliar as oportunidades de conhecimento e produção para o setor de proteínas terapêuticas, através do cenário mercadológico e análise prospectiva. Foram selecionadas as proteínas Betainterferona, Fator VIII, Filgrastima, Imiglucerase, Infliximabe e Somatropina para realização desse estudo, que não são produzidas no Brasil, estão presentes na lista de produtos estratégicos obtido por rota biológica e possuem alto custo para o Ministério da Saúde (MS).

Metodologia: O cenário mercadológico foi projetado através do processo de incorporação de informações, a partir de fontes confiáveis, para construção de uma visão técnica sobre o assunto. Para análise prospectiva foi utilizada como fonte de informação a base de patentes Derwent Innovations Index, utilizando como estratégia de busca palavras chaves e Classificação Internacional de Patentes para área biotecnológica: A61K, A61P e C12N. Foi utilizada uma ferramenta para mineração de texto (data mining), sendo adotado nesse estudo o programa VantagePoint 7.1. A geração dos mapas de conhecimento foi realizada através da correlação cruzada dos 20 maiores depositantes. Com o programa Aduna Cluster foi possível observa as conectividades existentes entre os depositantes, apresentando de forma clara as patentes depositadas como resultado das parcerias.

Resultados: Com a geração dos mapas de conhecimento identificou-se 15 clusters, sendo um cluster de Fator VIII, dois para Betainterferona e Infliximabe, três de Imiglucerase e Somatropina, além de quatro para Filgrastima. Para proteína Betainterferona destacouse a divisão Merck-Serono como depositante destaque do mercado. A avaliação para proteína Fator VIII identificou a empresa Baxter como central entre as parcerias com outras empresas, inclusive as conceituadas, demonstrando a busca pela liderança dessa empresa no mercado. Os resultados para proteína Filgrastima foram bastante vago devido 
à dificuldade de formação de clusters mais específico. No estudo da enzima Imiglucerase identificou-se a busca por produtos capazes de serem administrados em pacientes com a doença de Gaucher, porém que não são produtos biossimilares. Na avaliação para a proteína Infliximabe, identificou-se a busca por compostos orgânicos como alternativa para o tratamento de esclerose múltipla, além de observar que a empresa Centocor busca a manutenção de seu monopólio no mercado através dos depósitos de patentes. Provavelmente, devido à molécula Somatropina apresentar um grande número de produtos comercializados, foi relacionado um pequeno número de parcerias entre as empresas consolidadas.

Conclusão: As proteínas Imiglucerase e Infliximabe apresentaram melhores oportunidades de mercado no Brasil devido ao monopólio de produção, além da Betainterferona 1a baseado nos gastos do MS. Não existe uma empresa majoritária nos depósitos das proteínas estudadas, porém foi possível identificar que os principais depositantes de patentes foram as Big Pharmas, detentoras das tecnologias consolidadas, bem como as empresas portadoras de tecnologia de futuro, empresas emergentes ou spin-offs, sendo que essas últimas estão cada vez mais disputando o mercado com as grandes corporações. 